Case Report

\title{
Dysphagia Aortica: A Case Report and Review of Treatment Options
}

\author{
Komeil Mirzaei Baboli ${ }^{1}$, Sumeet K. Mittal ${ }^{1,2, *}$
}

1. Norton Thoracic Institute, St. Joseph's Hospital and Medical Center, Phoenix, Arizona, USA; EMails: Komeil.MirzaeiBaboli@dignityhealth.org; Sumeet.mittal@dignityhealth.org

2. Creighton University School of Medicine-Phoenix Regional Campus, Arizona, USA

* Correspondence: Sumeet K. Mittal; E-Mail: Sumeet.mittal@dignityhealth.org

Academic Editor: David G Smithard

Special Issue: Dysphagia in the Elderly

\section{OBM Geriatrics}

2021, volume 5, issue 1

doi:10.21926/obm.geriatr.2101157
Received: October 20, 2020

Accepted: February 03, 2021

Published: February 05, 2021

\begin{abstract}
A 64-year-old, cachectic man with body mass index (BMI) $<19$ visited in clinic with the chief complaint of dysphagia for 6 months. He reported a 2-year history of reflux and heartburn, for which he has been taking pantoprazole but reported only $40 \%$ relief of reflux symptoms. He reported progressive solid food mid-chest dysphagia. Additional comorbidities included severe pulmonary bronchiectasis and bullous emphysema and a history of treated pulmonary tuberculosis 40 years prior and two previous episodes of spontaneous pneumothorax in the right-sided lung treated with a chest tube. A chest X-ray showed a calcified aorta crossing the midline (Figure 1). A CT scan done for assessment of pneumothorax showed a torturous descending thoracic aorta and a dilated mid-/proximal esophagus. The diameter of the descending aorta was $41 \mathrm{~mm}$, and it crossed the midline. For evaluation of dysphagia, a barium swallow was performed, which showed a narrowing in the mid-esophagus with proximal dilation and lack of peristalsis (Figure 2). Upper gastrointestinal endoscopy showed a dilated esophagus with eccentric extraluminal compression. High-resolution manometry (HRM) showed an absence of peristalsis and a vascular pressure artifact around the midesophagus correlating with the external aortic compression (Figure 3). Due to alarming weight
\end{abstract}

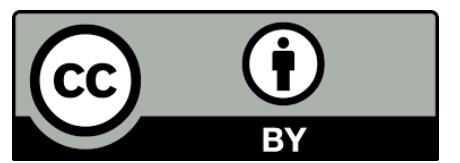

(C) 2021 by the author. This is an open access article distributed under the conditions of the Creative Commons by Attribution License, which permits unrestricted use, distribution, and reproduction in any medium or format, provided the original work is correctly cited. 
loss and a BMI $<19$, we recommended a feeding jejunostomy to maintain nutrition before scheduling definitive treatment.

\section{Keywords}

Aortic aneurysm; dysphagia; dysphagia aortica; vascular compression

\section{Introduction}

Dysphagia or difficulty in swallowing is a common problem, and patients frequently complain of choking, coughing, and an abnormal sensation of food sticking in the upper chest or the back of the throat. Intraluminal, intramural, or extramural pathology of the esophagus can cause dysphagia [1, 2].

Dysphagia aortica is a rare entity caused by extramural compression of the esophagus by a dilated, tortuous or aneurysmal aorta [3]. It has been associated with female sex, short stature, kyphosis, hypertension, and older age [4]. Presentation of extramural compression of the esophagus by the aorta ranges from asymptomatic to severe dysphagia [1].

Chest radiography, barium swallow, esophageal endoscopy, and manometry are useful tools for diagnosis, but in some patients, endoscopic or radiographic findings may be insignificant or absent [5]. There is no gold standard diagnostic test for dysphagia aortica, and a high suspicion index is helpful for diagnosis and treatment [1].

\section{Case Report}

A 64-year-old, cachectic man with body mass index (BMI) $<19$ visited in clinic with the chief complaint of dysphagia for 6 months. He reported a 2-year history of reflux and heartburn, for which he has been taking pantoprazole but reported only $40 \%$ relief of reflux symptoms. He reported progressive solid food mid-chest dysphagia and did not receive any rehabilitation therapy. Additional comorbidities included severe pulmonary bronchiectasis and bullous emphysema and a history of treated pulmonary tuberculosis 40 years prior and two previous episodes of spontaneous pneumothorax in the right-sided lung treated with a chest tube.

A chest X-ray showed a calcified aorta crossing the midline (Figure 1). A CT scan done for assessment of pneumothorax showed a torturous descending thoracic aorta and a dilated mid/proximal esophagus. The diameter of the descending aorta was $41 \mathrm{~mm}$, and it crossed the midline. For evaluation of dysphagia, a standard liquid barium swallow followed by a solid phase with a 10 $\mathrm{mm}$ to $13 \mathrm{~mm}$ barium tablet and a bread bolus was performed, which showed a narrowing in the mid-esophagus with proximal dilation and lack of peristalsis (Figure 2). Upper gastrointestinal endoscopy showed a dilated esophagus with eccentric extraluminal compression. High-resolution manometry (HRM) showed an absence of peristalsis and a vascular pressure artifact around the mid-esophagus correlating with the external aortic compression (Figure 3). Due to alarming weight loss and a $\mathrm{BMI}<19$, we recommended a feeding jejunostomy to maintain nutrition before scheduling definitive treatment. 


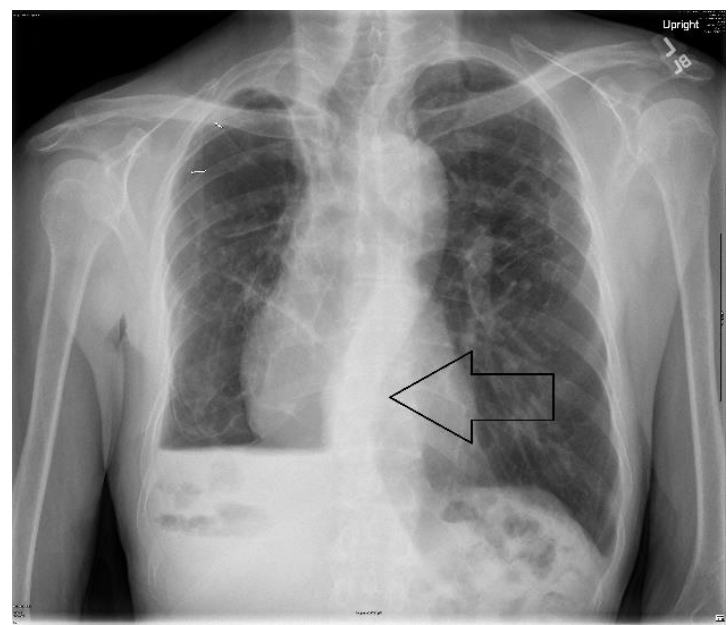

Figure 1 Chest X-ray shows calcified aorta.

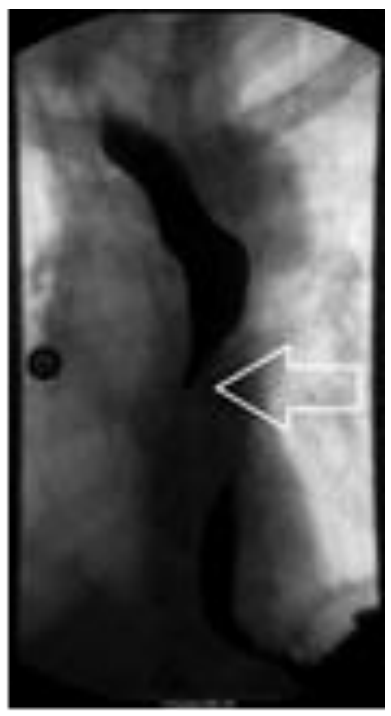

Figure 2 Barium swallow shows a narrowing in the mid-esophagus with proximal dilation and lack of peristalsis.

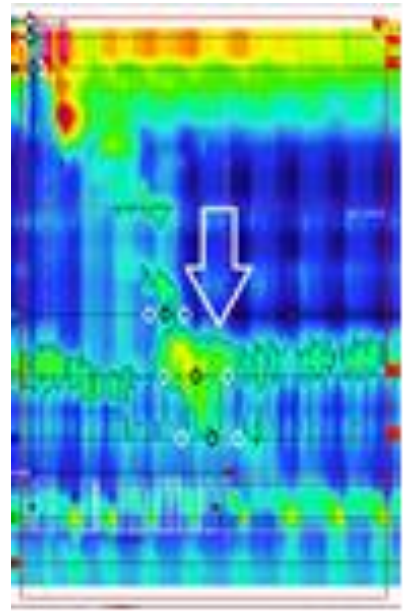

Figure 3 High-resolution manometry shows an absence of peristalsis and a vascular pressure artifact around the mid-esophagus. 


\section{Discussion}

Dysphagia is a common problem in the elderly, and the elderly population in the US will increase from 39 million to 69 million from 2010 to 2030 [6]. Aging causes muscle mass reduction and connective tissue loss, which may result in a weaker swallow. These changes can negatively impact the swallowing process. The approach to dysphagia in the elderly requires taking a full history and performing a physical exam. In general, patients with solid food dysphagia suffer from an obstruction-like stricture, ring, or web, and those with liquid dysphagia are more likely to have neuromuscular problems. Dysphagia can be assessed as oropharyngeal, or esophageal, or a combination of both. Esophageal dysphagia is divided into two types: structural and functional. Structural problems include an esophageal web or ring, peptic stricture, esophageal malignancy, and vascular compression (dysphagia lusoria and aortica). Functional problems include inflammatory disorders like erosive esophagitis, achalasia, distal esophageal spasm, outflow obstruction, and ineffective esophageal motility [6].

The term dysphagia aortica was first coined by Pape [7] in 1939 for difficulty in swallowing caused by external compression of the esophagus by a tortuous, ectatic, or aneurysmal aorta associated with age-related degeneration.

Another rare cause of dysphagia due to cardiovascular compression, dysphagia megalatriensis, has been described in a case report [8]. This type of dysphagia is caused by extrinsic compression from a dilated left atrium. Esophageal narrowing by an aberrant subclavian artery is eponymously termed dysphagia lusoria and is a congenital condition [8].

Although dysphagia aortica almost always occur in older patients, it has been reported in a 29year-old man secondary to an aortic pseudo aneurysm [9].

As mentioned earlier, there is no gold standard for diagnosis of dysphagia aortica [4]. Barium swallow, chest CT, gasteroduodenoscopy, and HRM can be useful diagnostic tools, but a high suspicion index is necessary for diagnosis $[3,5]$. If extrinsic compression of the esophagus is seen in the esophagoscopy, a contrast CT scan of thorax may be considered to exclude an abnormal vascular ring [10]. In a case report by Dejaeger et al [11], an aneurysm of the aorta causes pseudoachalasia, but the most common etiology of pseudoachalasia is malignant involvement of the esophagus, underlining the necessity of upper endoscopy in patients with dysphagia. The cause of dysphagia and its exact mechanism should be diligently pursued and not attributed to "aging."

Symptoms of aortic compression on the esophagus range from none to severe. Figure 4 shows a CT image for a patient with a tortuous aorta, a pressure artifact in the distal esophagus was also noted on HRM. The patient did not report dysphagia. Asymptomatic patients identified incidentally need no further assessment from an esophageal perspective though may need intervention for a thoracic aortic aneurysm. Note that a calcified aorta, which is of otherwise normal caliber and nontorturous, should not cause esophageal obstruction. Mild cases of dysphagia aortica are treated conservatively, because patients are often elderly and have multiple comorbidities. Conservative treatments include diet modification like soft and liquid foods, avoidance of solid and sticky meals, careful chewing, and not lying down after eating or taking medications. In patients with severe symptoms or in those unresponsive to conservative treatment, either a feeding tube or more radical surgery can be considered [3-4, 12]. A sub-sternal gastric pull up, with or without esophageal resection, may alleviate dysphagia; however, the procedure carries significant morbidity. Once recovered from surgery, the dysphagia is usually resolved and no further treatment is needed. 


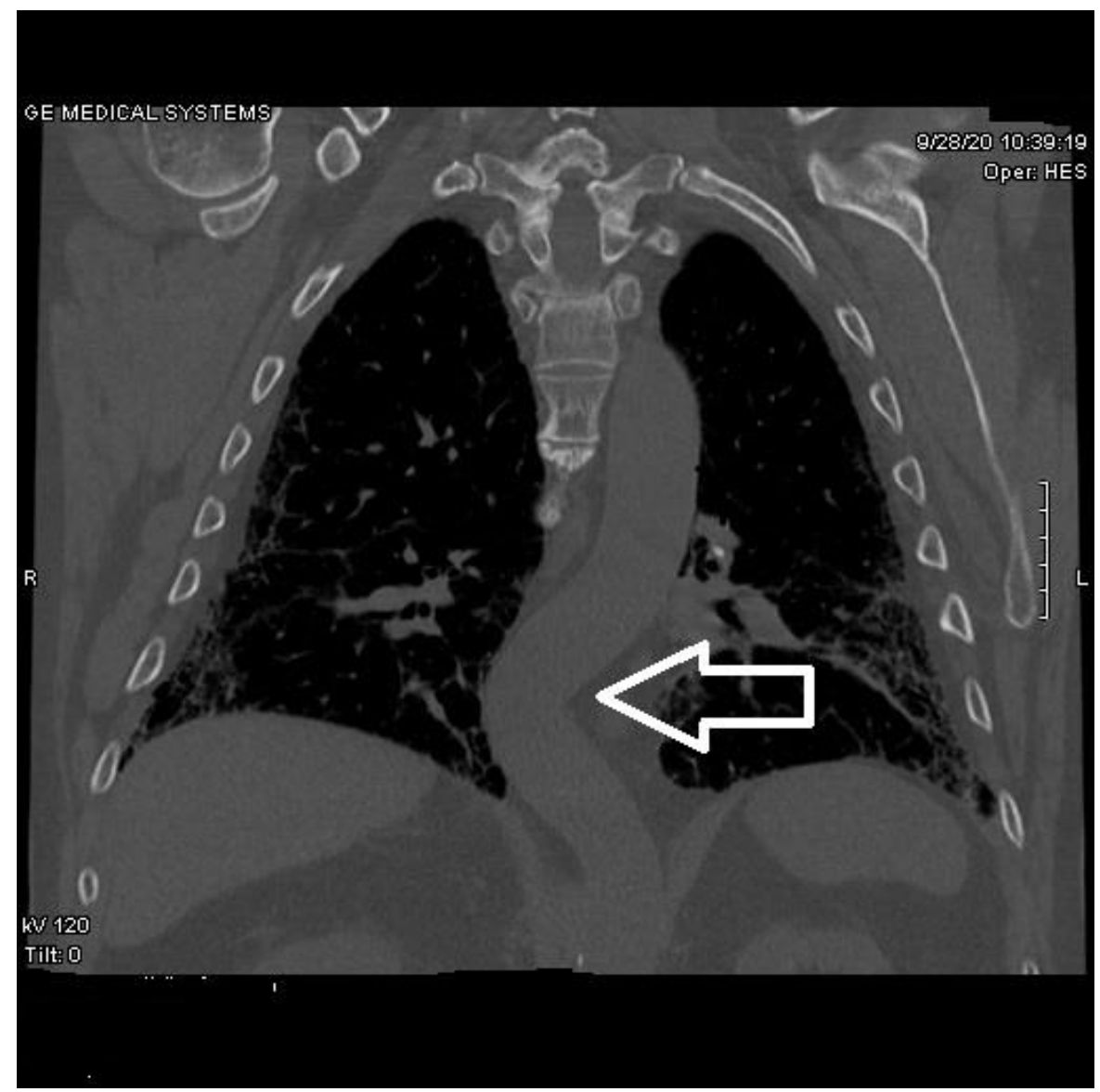

Figure 4 Computed tomography shows the aorta crosses the midline, but no dysphagia was reported.

For patients who are not a candidate for surgery, thoracic aortic stent repair or thoracic endovascular aortic repair (TEVAR) $[13,14]$ or a percutaneous endoscopic gastrostomy tube should be considered [13]. Hybrid stenting therapy is another treatment option for dysphagia aortica due to a thoracic aortic aneurysm. Okamura et al [15] reported a case that was treated with double stenting of the aorta and esophagus, and the patient's symptoms improved after intervention.

In conclusion, dysphagia aortica is a diagnosis of exclusion; to confirm the diagnosis, we should first exclude other causes of dysphagia like malignancy, stricture, or a motility disorder. It is important to never ignore dysphagia due to aging.

\section{Acknowledgments}

The authors thank Kristine Nally for help with editing and manuscript preparation.

\section{Author Contributions}

Komeil Mirzaei Baboli: collect data, write the manuscript. Sumeet Mittal: collect data, write the manuscript, final edition.

\section{Competing Interests}

The authors have nothing to disclose with regard to commercial support. 


\section{References}

1. Sharma M, Singh P, Kirnake V, Toshniwal J, Chopra A. Dysphagia aortica: Emerging role of endoscopic ultrasound (with videos). Endosc Ultrasound. 2018; 7: 343-346.

2. Spieker MR. Evaluating dysphagia. Am Fam Physician. 2000; 61: 3639-3648.

3. Song SW, Chung JH, Kim SH. A case of dysphagia aortica in an elderly patient. Int J Gerontol. 2012; 6: 46-48.

4. Badila E, Bartos D, Balahura C, Daraban AM. A rare cause of dysphagia-dysphagia aorticacomplicated with intravascular disseminated coagulopathy. Maedica (Bucur). 2014; 9: 83-87.

5. Wilkinson JM, Euinton HA, Smith LF, Bull MJ, Thorpe JA. Diagnostic dilemmas in dysphagia aortica. Eur J Cardiothorac Surg. 1997; 11: 222-227.

6. Khan A, Carmona R, Traube M. Dysphagia in the elderly. Clin Geriatr Med. 2014; 30: 43-53.

7. Pape R. Uber einen abnormen verlauf ('tiefe Rechtslage') der mesa aotitischen aorta descendens. Fortschr Roetgenstr. 1932; 46: 254-269.

8. Hsu YC, Wu SS, Yen HH. An unusual cause of dysphagia in an elderly woman: Dysphagia megalatriensis. Am J Med Sci. 2019; 358: e1-e2.

9. Al-Quthami A, Albloushi A, Alquthami AH. Images in vascular medicine. Dysphagia aortica with left atrial compression. Vasc Med. 2015; 20: 266-267.

10. Liao CY, Huang SC, Wang YC, Chin HK, Tsai CC, Ben RJ, et al. Dysphagia aortica: A fatal delay in diagnosis. Am J Emerg Med. 2015; 33: 1117.e3-e5.

11. Dejaeger $M$, Lormans $M$, Dejaeger E, Fagard K. Case report: An aortic aneurysm as cause of pseudoachalasia. BMC Gastroenterol. 2020; 20: 1-5.

12. Hilliard AA, Murali NS, Keller AS. Dysphagia aortica. Ann Intern Med. 2005; 142: 230-231.

13. Cambria RP, Brewster DC, Lauterbach SR, Kaufman JL, Geller S, Fan CM, et al. Evolving experience with thoracic aortic stent graft repair. J Vasc Surg. 2002; 35: 1129-1136.

14. Choi SH, Yang GK, Gagnon J. Dysphagia aortica secondary to thoracoabdominal aortic aneurysm resolved after endograft placement. J Vasc Surg Cases Innov Tech. 2019; 5: 501-505.

15. Okamura K, Suematsu Y, Morizumi S, Kawata M. Hybrid stenting therapy for dysphagia aortica with Rokitansky's diverticulum concomitant with thoracic aortic aneurysm. Eur J Cardiothorac Surg. 2015; 47: e229-e231. 
OBM Geriatrics 2021; 5(1), doi:10.21926/obm.geriatr.2101157

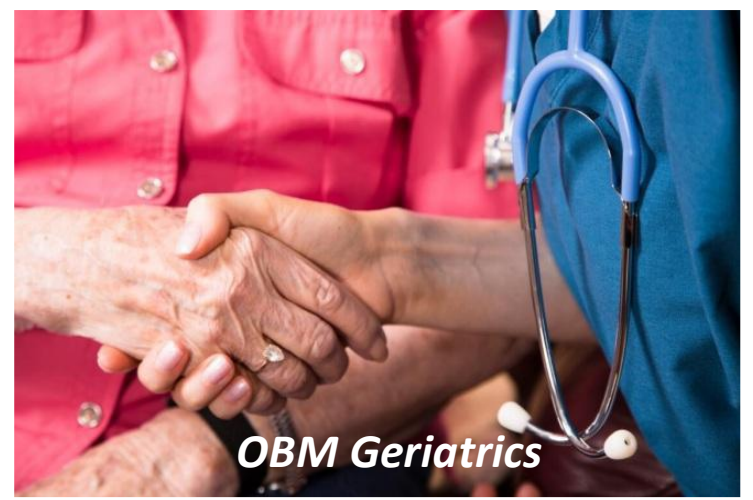

Enjoy OBM Geriatrics by:

1. Submitting a manuscript

2. Joining in volunteer reviewer bank

3. Joining Editorial Board

4. Guest editing a special issue

For more details, please visit:

http://www.lidsen.com/journals/geriatrics 